\title{
Statistical evolution of clinical laboratories in patients admitted to the CECCS with SARS-COV-2
}

\section{Evolución estadística de laboratorios clínicos en pacientes ingresados en el CECCS con SARS-COV-2}

\author{
YAÑEZ-VARGAS Israel†*, PRIETO-GARCÍA Daniela, DOÑATE-ÁLVAREZ Andrea and \\ QUINTANILLA-DOMINGEZ Joel
}

Universidad Politécnica de Juventino Rosas, Departamento de Ingeniería en Redes y Telecomunicaciones.

ID $1^{\text {st }}$ Author: Juan Israel Yañez Vargas / ORC ID: 0000-0001-5749-8442, CVU CONACYT ID: 295711

ID $1^{\text {er }}$ Coauthor: Daniela Prieto García / ORC ID: 0000-0002-1228-7163

ID $1^{\text {st }}$ Coauthor: Andrea Abigail Doñate Álvarez / ORC ID: 0000-0003-4005-8533

ID $2^{\text {nd }}$ Coauthor: Joel Quintanilla Domínguez/ ORC ID 0000-0003-2442-2032, CVU CONACYT ID: 165237

DOI: $10.35429 / J Q S A .2021 .22 .8 .1 .10$

Received March 14, 2021; Accepted June 29, 2021

\begin{abstract}
The evolution of the SARS-CoV-2 Virus in recent months in the world and especially in Mexico has also created changes in the patient's treatment and their laboratory studies, as is the case of patients admitted to the CECCS in Salamanca, Guanajuato, in which after months of caring for COVID-19 patients, new relevant laboratory studies were added (Ferritin and D-Dimer), therefore updates were made in statistical analyzes, and day-to-day behavior. The study is based on updating and cleaning the database, taking a sample of more patients with COVID-19, statistical analysis including admission tables, Body Mass Index, Variance, Normalization, relationship between the first day and the last day of patients who died and lived. The main idea of the work is to learn with more detail those laboratories that contain information to study in the future if there is a relationship between any medication supplied with the improvement or aggravation of the patient.
\end{abstract}

SARS-COV-2, Statistics evolution, Clinical laboratories

\begin{abstract}
Resumen
La evolución del Virus SARS-CoV-2 en los últimos meses en el mundo y especialmente en México ha creado también cambios en el tratamiento de los pacientes y sus estudios de laboratorio, como es el caso de los pacientes ingresados en el CECCS de Salamanca, Guanajuato, en el que después de meses de atención a pacientes COVID-19 se agregaron nuevos estudios de laboratorio relaventes (Ferritina y Dimero D), por lo anterior se realizaron actualizaciones en análisis estadísticosm, y el comportamiento del día a día. El estudio se basa en la actualización y limpieza de la base de datos, toma de muestra de más pacientes con COVID-19, análisis estadístico incluyendo tablas de ingreso, Índice de Masa Corporal, Varianza, Normalización, relación entre el primer día y último de los pacientes que fallecieron y vivieron. La idea principal del trabajo es conocer más a detalle aquellos laboratorios que contengan mayor información para estudiar a futuro si existe relación entre algún medicamento suministrado con la mejora o agravamiento del paciente.
\end{abstract}

SARS-CoV-2, Evolución estadística, Laboratorios clínicos

Citation: YAÑEZ-VARGAS Israel, PRIETO-GARCÍA Daniela, DOÑATE-ÁLVAREZ Andrea and QUINTANILLADOMINGEZ Joel. Statistical evolution of clinical laboratories in patients admitted to the CECCS with SARS-COV-2. Journal of Quantitative and Statistical Analysis. 2021. 8-22: 1-10

\footnotetext{
* Correspondence to Author (e-mail: jyanez_ptc@upjr.edu.mx)

$\dagger$ Researcher contributing as first author.
} 


\section{Introduction}

More than a year has passed in which the country of Mexico started a mandatory quarantine due to the pandemic that still continues to affect the world, the pandemic that originated at the end of 2019 in China and is called Severe Acute Respiratory Syndrome (SARS-CoV-2) or also known as COVID-19.

The increase in cases and deaths has meant a great struggle to be able to contain the virus, for which great efforts have been made to obtain the best vaccines, the best medications, and know the behavior or evolution of patients, despite all the above, the problems derived from COVID-19 and how it affects the body (Coronavirus disease (COVID-19)) are still not fully understood.

The Ministry of Health of Mexico in its daily press conference made a cut on COVID-19 in which they show a figure of 2 million 397 thousand 307 infected, likewise 221 thousand 695 deaths confirmed by the virus (Coronavirus - gob.mx) . For the case study to be carried out, it was determined to extract information from the State Center for Critical Care of Salamanca (CECCS), being a third-level hospital that only receives patients with COVID-19 from the state of Guanajuato and that has the peculiarity of receiving serious patients.

The information that will be extracted from the CECCS will be of great relevance for conducting multiple studies on patients who have or have had COVID-19, since it is still complex to know its behavior in humans ("Coronavirus Guanajuato", 2020). Derived from the above, multiple studies and research of the disease have been carried out through X-ray image analysis or tomography, as well as statistical analyzes that seek a greater understanding of the disease, as is the case of some relevant ones that are mentioned below. continuation.

According to the study (Gao et al., 2020) performs an analysis of laboratory data for a differential diagnosis of COVID-19 patients, the study was for 28 seriously ill adult patients and 19 laboratories for each patient including Dimero-D and Ferritin.
Likewise, Yun et al. (2020, 95 p) in his article he performs a statistical study of clinical laboratories of 2510 patients, in which he describes the tests carried out influenza type A and influenza type B, graphs of the studies carried out and comparisons with others that were performed are shown. have done blood studies. In the study by Rodriguez-Morales et al. (2020) a meta-analysis of multiple research articles on COVID-19 throughout the world is carried out, in which they compare laboratory studies of confirmed patients and X-ray images and Tomographs, the idea is to calculate the prevalences, performing qualitative and quantitative studies of the articles reviewed.

In the article by Liu et al. (2020, p.372) a study was carried out on 12 patients hospitalized with COVID-19, the research aims to show the changes in patients based on their laboratories, medications supplied and X-ray and tomography studies.

Previously, a research article was carried out (Yañez-Vargas, Doñate-Álvarez, Quintanilla-Domínguez, \& Aguilera-González, 2020), in which the first statistical studies of the patients admitted to the CECCS were carried out, having studies of the patients with 28 clinical laboratories. The day-to-day study of the patients was carried out with the most outstanding graphics of the patients who died and lived.

Previous investigations carry out statistical studies of the disease but do not have more than 20 laboratory studies, while the present work aims to carry out the study by expanding the laboratory data and focusing on a sample of critically ill patients from the state of Guanajuato.

\section{Material and methods}

The patients who are admitted to the CECCS must come from second level health institutions, which carry out studies and previous diagnoses to know the severity of each of the patients, so if with the passage of time the patients begin to worsen they are carried out transfers to the CECCS, where upon entering the institution, as a first step, different vital signs and relevant information such as age, weight and previous illnesses must be taken. 
The information extracted from the CECCS corresponds to 109 patients, who were admitted from March 24 to October 20, 2020, adding that the first patient in the state with symptoms of COVID-19 was admitted to said center.

Based on the information that has been extracted, a study was carried out to find out statistics of the information of the admitted patients, due to the above, the table of total patients who were admitted in the aforementioned time is shown in Table 1 , in which A breakdown of how many have died and how many have been discharged is shown, it is important to mention that the CECCS is a thirdlevel center in which the most serious patients arrive in the state, which is why it has a mortality rate higher.

\begin{tabular}{|c|c|c|c|c|c|}
\hline \multicolumn{6}{|c|}{ Total patients classification } \\
\hline & \multirow{2}{*}{ Patients } & \multirow{2}{*}{ Deaths } & \multicolumn{2}{|c|}{ Patient was discharged } & \multirow{2}{*}{ Hospitalized } \\
\hline & & & $\begin{array}{l}\text { Counter } \\
\text { reference }\end{array}$ & Reference & \\
\hline Covid 19 & 88 & 40 & 28 & 13 & 7 \\
\hline Negatives & 18 & 8 & 8 & 2 & 0 \\
\hline Pending & 3 & 2 & 1 & 0 & 0 \\
\hline Total & 109 & 50 & 37 & 15 & 7 \\
\hline \multicolumn{6}{|c|}{ All the female discharged Totals $=52$} \\
\hline
\end{tabular}

Table 1 Total income in the CECCS

Source: Own

Likewise, Table 2 shows the classification of men who have been admitted at the same time of analysis, you can see the number of patients with COVID-19, those who lived and those who were discharged.

\begin{tabular}{|c|c|c|c|c|c|}
\hline \multicolumn{6}{|c|}{ Male patients classification } \\
\hline & \multirow[t]{2}{*}{ Patients } & \multirow[t]{2}{*}{ Deaths } & \multicolumn{2}{|c|}{ Patient was discharged } & \multirow[t]{2}{*}{ Hospitalized } \\
\hline & & & $\begin{array}{l}\text { Counter } \\
\text { reference }\end{array}$ & Reference & \\
\hline Covid 19 & 60 & 27 & 18 & 10 & 5 \\
\hline Negatives & 11 & 6 & 4 & 1 & 0 \\
\hline Pending & 2 & 2 & 0 & 0 & 0 \\
\hline Total & 73 & 35 & 22 & 11 & 5 \\
\hline \multicolumn{6}{|c|}{ All the female discharged Totals $=33$} \\
\hline
\end{tabular}

Table 2 Income of men to the CECCS Source: Own

Table 3 shows the classification of women who have been admitted at the same time of analysis, you can see the number of patients with COVID-19, those who lived and those who were discharged, as explained in the article (Yañez-Vargas et al., 2020), which shows the trend of resistance of women to COVID-19.

\begin{tabular}{|c|c|c|c|c|c|}
\hline \multicolumn{6}{|c|}{ Female Patients classification } \\
\hline & \multirow[t]{2}{*}{ Patients } & \multirow[t]{2}{*}{ Deaths } & \multicolumn{2}{|c|}{ Patient was discharged } & \multirow{2}{*}{ Hospitalized } \\
\hline & & & $\begin{array}{l}\text { Counter } \\
\text { reference }\end{array}$ & Reference & \\
\hline Covid 19 & 28 & 13 & 10 & 3 & 2 \\
\hline Negatives & 7 & 2 & 4 & 1 & 0 \\
\hline Pending & 1 & 0 & 1 & 0 & 0 \\
\hline Total & 36 & 15 & 15 & 4 & 2 \\
\hline \multicolumn{6}{|c|}{ All the female discharged Totals $=19$} \\
\hline
\end{tabular}

Table 3 Income of women to CECCS

Source: Own

According to the fact that when patients are admitted to the CECCS, relevant information such as weight, age and height are collected, a study of the Body Mass Index (BMI) has been carried out, with the intention of obtaining relevant information and statistics from all patients, which can be used for future knowledge processes of the behavior of the virus in humans.

In Graph 1 it is possible to see the general BMI, it is important to mention that the normal value of BMI is between 19 and 24, so very high values are shown in most patients, reaching cases of grade III obesity, which is makes it relevant in the COVID-19 study.

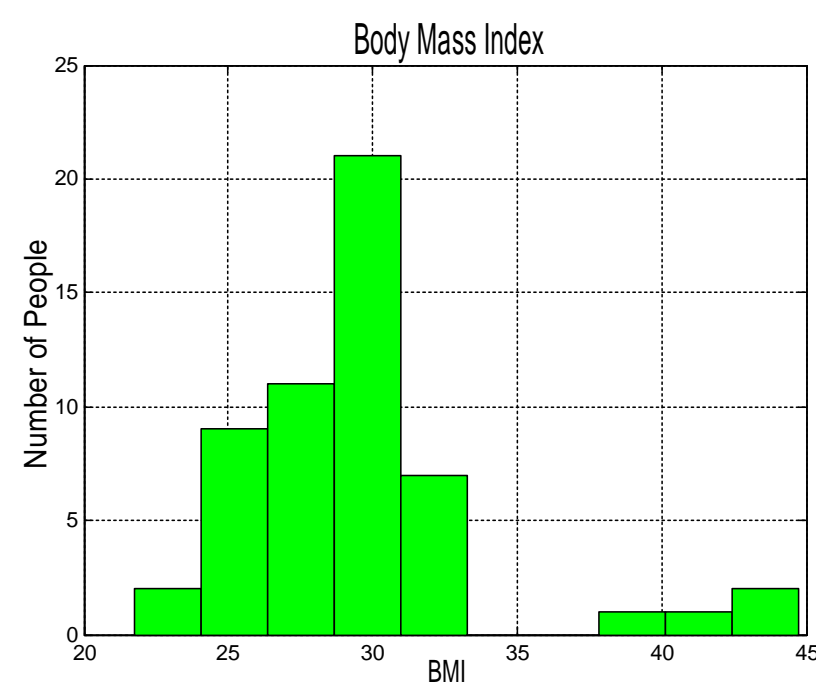

Graph 1 BMI in CECCS patients Source: Own

\section{Clinical laboratories}

Unlike the article (Yañez-Vargas et al., 2020) in which 29 laboratories were used, now we work with 34 laboratories that are mentioned below: Glucose, Urea, Ureic Nitrogen, Creatinine, Total Proteins, Albumin, Globulin, A / G Ratio, Alanine Amino Transferase, Aspartate Amino Transferase, Total Bilirubin, Direct Bilirubin, Indirect Bilirubin, Lactic Dehydrogenase, Creatine Phosphokinase, Chlorine, Potassium, Sodium, Hematic Cytometry, Prothrombin Time, Thromboplastin Time, 
Procalithin, Fibrin Calcium, Phosphorus, Alkaline Phosphate, Magnesium, Protein C. Reactive and Total Cholesterol, HDL Cholesterol, Sedimentation Rate were added, in addition 2 that have gained great relevance in recent months and are Dimero D and Ferritin (Pagana \& Pagana, 2015 ).

\section{Methodology}

For the development of this statistical study, it is necessary to propose a series of steps that are described in the block diagram of Figure 1 that describes all the steps carried out in the investigation.

The first block corresponds to obtaining / extracting the clinical laboratories of the patients admitted to the CECCS, the second step is the analysis of the information and how it will be its subsequent classification and division (men / women) which is expressed In the third block, having the information classified, an organization of the information is carried out and a subsequent normalization of the data that is shown in blocks 4 and 5 , it is important to highlight that the normalization has been carried out based on the maximum values and minimums of each laboratory, taking into account that the normalization will be applied to each laboratory separately, likewise in the organization of the data, the use of the mean and mode has been proposed to complete missing information from laboratories (Gonzalez \& Woods, 2008).

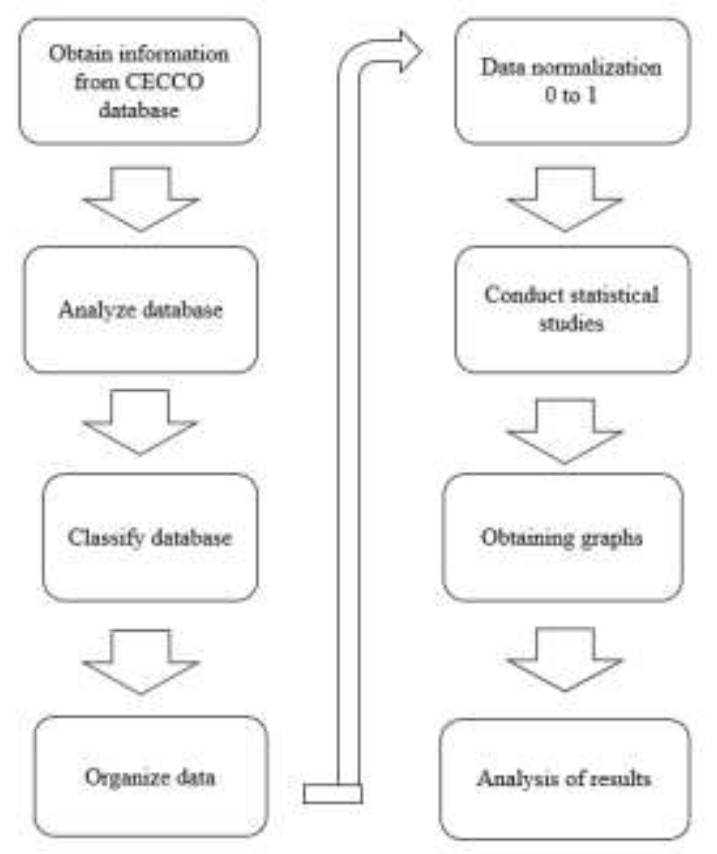

Figure 1 General block diagram Source: Own

\section{Results}

Block 6 represents the statistical study of data from clinical laboratories, a study of variance of the data is required to analyze the relevance of the information, as well as day-to-day studies of multiple laboratories, similarity studies between patients and their behaviors during their stay at the CECCS to finally obtain the multiple graphs required for subsequent analysis and conclusions, all under the supervision of a doctor who is working in the hospital (Devore, 2012), (Johnson et al. , 2012).

\begin{tabular}{|c|c|c|}
\hline Number & Laboratory & Variance \\
\hline 1 & Ferritin & 83395211.83 \\
\hline 2 & D- Dimer & 4083609.155 \\
\hline 3 & C Reactive Protein & 3857759.202 \\
\hline 4 & Creatin-Fosfocinasa & 793769.7153 \\
\hline 5 & Fibrinogen & 115711.6071 \\
\hline 6 & Lactic Dehydrogenase & 33699.79234 \\
\hline 7 & General Urine Test & 27041.14802 \\
\hline 8 & Glucose mg/dl & 7122.691524 \\
\hline 9 & Alkaline phosphatase & 3360.290893 \\
\hline 10 & Urea $\mathrm{mg} / \mathrm{dl}$ & 2986.325801 \\
\hline 11 & Chlorine & 2088.983047 \\
\hline 12 & Aspartate aminotransferase & 1434.218558 \\
\hline 13 & Alanine aminotransferase & 1293.928146 \\
\hline 14 & Total Cholesterol & 1041.130814 \\
\hline 15 & Ureic Nitrogen & 532.8210967 \\
\hline 16 & Albumin & 314.4155434 \\
\hline 17 & Sedimentation rate & 196.0301266 \\
\hline 18 & Potassium & 176.5350151 \\
\hline 19 & HDL Cholesterol & 101.3912015 \\
\hline 20 & Sodium & 97.37544607 \\
\hline 21 & Partial thromboplastin time & 37.8615637 \\
\hline 22 & Creatinine $\mathrm{mg} / \mathrm{dl}$ & 35.65593406 \\
\hline 23 & Hematic Cytometry & 21.8262548 \\
\hline 24 & Indirect bilirubin & 19.89173877 \\
\hline 25 & Prothrombin time & 15.65751113 \\
\hline 26 & Procalcitonin & 9.634289823 \\
\hline 27 & Phosphorus & 2.690131457 \\
\hline 28 & Calcium & 2.564005621 \\
\hline 29 & Total Bilirubin & 1.04556895 \\
\hline 30 & Total Proteins & 0.92483412 \\
\hline 31 & Magnesium & 0.568098256 \\
\hline 32 & Relation $\mathrm{A} / \mathrm{G}$ & 0.508733212 \\
\hline 33 & Globulin & 0.431637386 \\
\hline 34 & Direct Bilirubin & 0.331210161 \\
\hline
\end{tabular}

Table 4 Variance study of clinical laboratories Source: Own

In the area of medicine, statistical analysis of the behavior of patients in the face of all diseases, symptoms, surgeries and medications is of great relevance, and if at the same time graphs are made that interpret all the processed information, it will be easier to know the COVID -19 and its behavior in a sample of patients from the state of Guanajuato, which also, as an important point, the sample is also taken from critically ill patients with tendencies to die due to their comorbidities, genetics and lifestyle. 
Table 1 shows an analysis of variance that has been carried out to the clinical laboratories of patients admitted to the CECCS, it is important to comment that the study of variance will help to measure the greater or lesser dispersion of information or data values Regarding the arithmetic mean that the same data have, the study has been carried out for each of the laboratories. The Table was accommodated from greater variance to less variance, observing that two of the new laboratories added (Ferritina and Dimero D) in the investigation are the ones with the greatest dispersion, this becomes relevant because large changes have been identified in those laboratories between patients who live and die, while the laboratories with the lowest variance correspond to Globulin and Direct Bilirubin.

The study is a part of multiple analyzes that will be used to know what information / laboratories can be relevant as inputs in classifiers and thus be able to reduce errors or computational complexity for the design of artificial neural network architectures.

At the same time that Table 1 has been made, several graphs were created that represent the values obtained from the variances of each laboratory, in Graph 2 it is possible to observe the 34 clinical laboratories on the $\mathrm{X}$ axis, the order is according to the taking of analysis carried out by the doctors and nurses of the CECCS, while the value obtained from the variance is observed on the $\mathrm{Y}$ axis. According to the graph, it is widely noted that laboratory 30 that corresponds to Ferritin is the one with the greatest variance, followed by laboratory 29 , which is Dimero D, laboratory 28 continues, which is C-Reactive Protein and finally the creatine phosphosinase that is represented in the lab 15 from the same graph.

In the case of Graph 3, the Ferritin laboratory was eliminated to see the values of the other laboratories, since there are extra tests that can be used for a subsequent classification through some artificial intelligence method. Given the above, the relevance of lactic dehydrogenase, Procalcitotin and general urine examination are visualized in the graph.

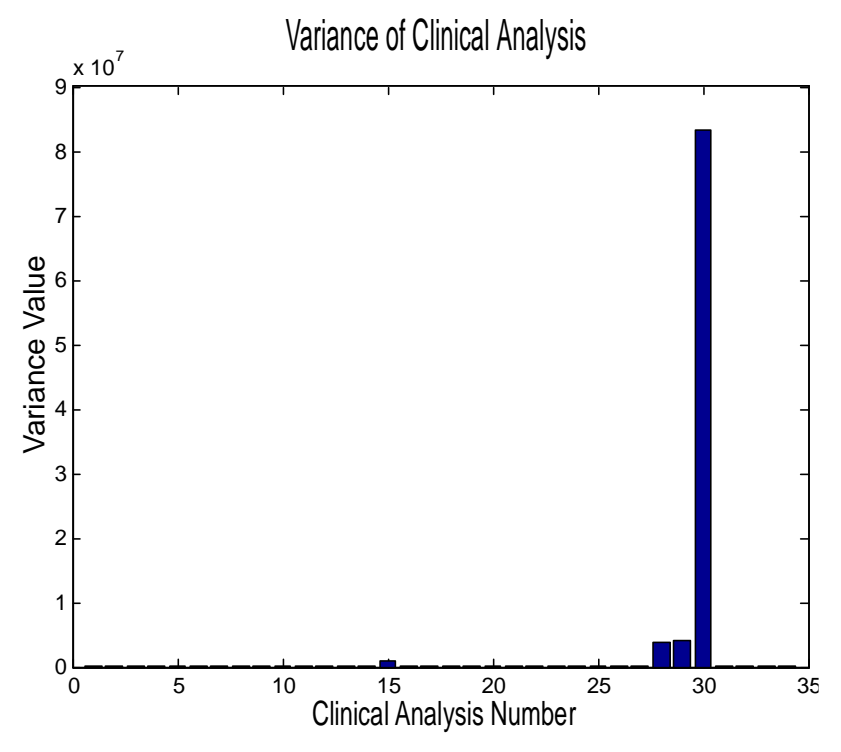

Graph 2 Variance graph of clinical laboratories Source: Own [Matlab]

The analysis carried out previously shows the changes proposed at the international level in which it was proposed to add laboratory studies of Dimero D and Ferritin to patients with COVID-19, observing their relevance through the first study of variance and will serve as a basis for future research in critical patients in the state of Guanajuato.

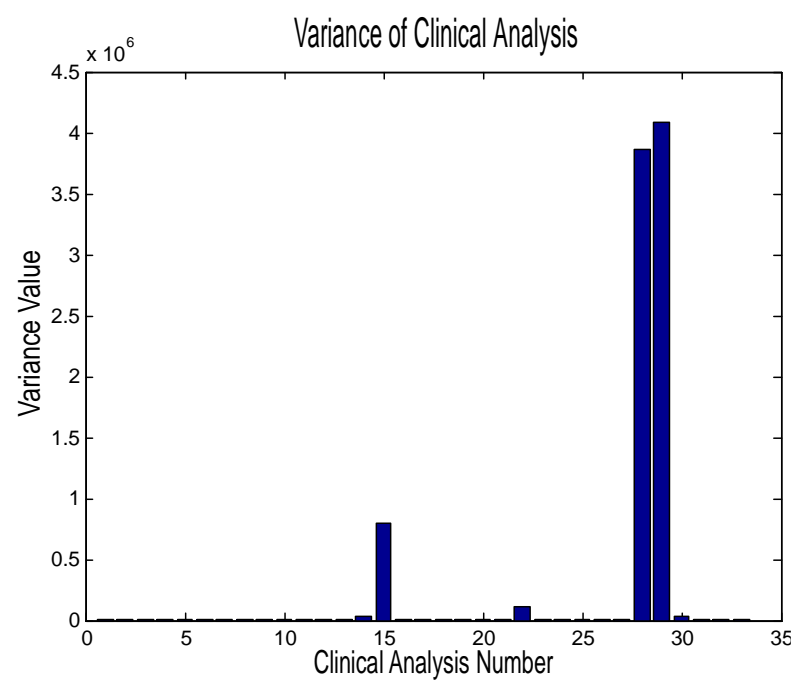

Graph 3 Variance graph of clinical laboratories without Ferritin Source: Own [Matlab]

The second section of statistical analysis of clinical laboratory data of patients with COVID-19 focused on finding the relevance of the two new laboratories and their behavior in patients admitted to the CECCS. 
As an important note, it should be mentioned that both laboratories are obtained on average every 5 or 6 days, so in patients who were hospitalized for a short time, there are not so many samples, so those patients who were admitted for around 40 days are those of which a study could be carried out in a better way.

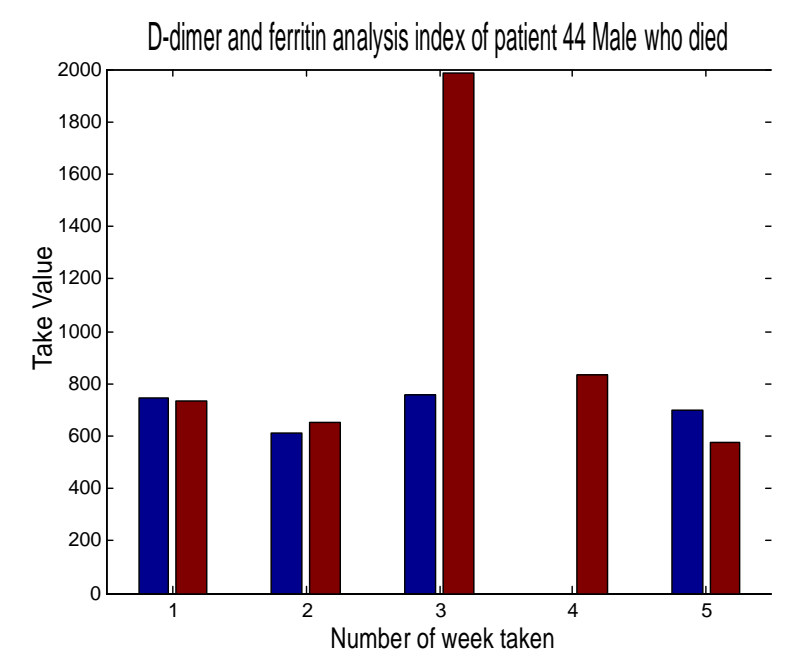

Graph 4 Dimero D and Ferritin analysis in patient 44 Source: Own [Matlab]

Graph 4 represents patient number 44 who had a stay of 22 days, the patient was taken 4 samples of Dimero D and is represented with the blue color in the bar graph, while 6 samples of Ferritin were taken represented in red color throughout his stay, observing that Dimero D remained with slight changes, while Ferritin reached very high values that caused decompensation of the patient. Patient 44 is a man who unfortunately died, the graph shows that the changes shown in Ferritin are important signs in the relapses of patients.

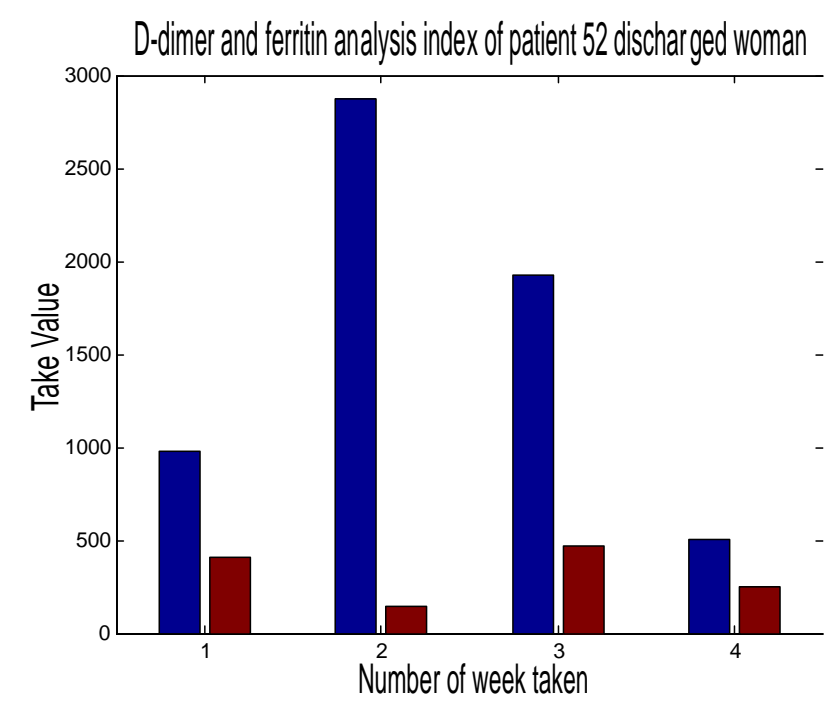

Graph 5 Dimero D and Ferritin analysis in patient 52 Source: Own [Matlab]
For Graph 5 represents patient number 52 who had a stay of 42 days, the patient was taken 4 samples of Dimero D and is represented with the blue color in the bar graph, while 4 samples of Ferritin were taken represented in red color throughout its stay, observing that Dimero D remained with high values in the second sample, reaching a considerable decrease in the last sample in Dimero D and Ferritina. Patient 52 is a woman who was discharged, showing that keeping both laboratories low helps patients, it will be necessary to analyze what causes sudden changes in both.

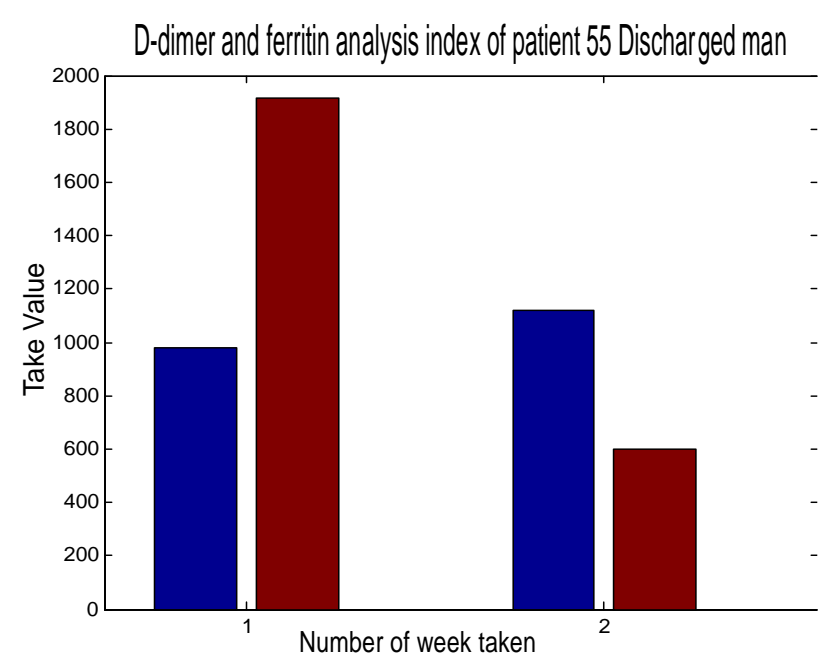

Graph 6 Dimero D and Ferritin analysis in patient 55 Source: Own [Matlab]

Graph 6 represents patient number 55, who had a stay of 8 days, the patient was taken two samples of Dimero D and is represented with the blue color in the bar graph, while two samples of Ferritin were taken represented in red color throughout their stay, observing that Dimero D and Ferritin had high values in the first sample, while Dimero D rose for the second sample and Ferritin decreased considerably.

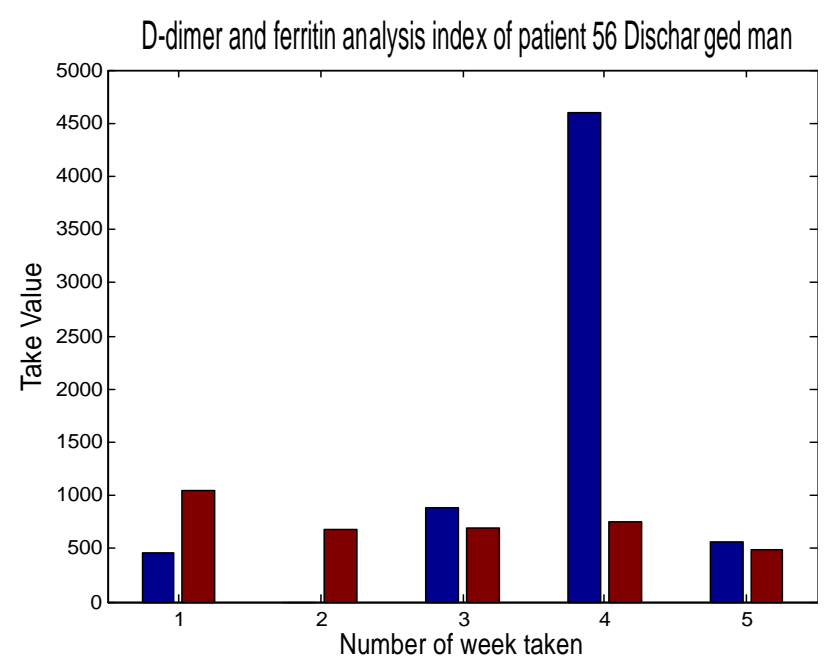

Graph 7 Dimero D and Ferritin analysis in patient 56 Source: Own [Matlab] 
In the case of Graph 7, we have patient number 56, who had a stay of 26 days hospitalized, the patient was taken 4 samples of Dimero D and is represented with the blue color in the bar graph, while took 6 samples of Ferritin represented in red throughout their stay, observing that Dimero D and Ferritin maintain constant and low values, except for sample number 4 of Dimero D that a stronger change was observed but managed to reduce it in the next sample. The male patient was subsequently discharged.

Finally, Graph 8 shows patient 60 who died at the end of his stay, the patient was hospitalized for 11 days, for which there are only two samples taken of Dimero D and Ferritin, in both cases they have values above 800 in average in the first sample and in the second sample Dimero D increases and Ferritin does not fall below 1000, which is still a high value for normal values.

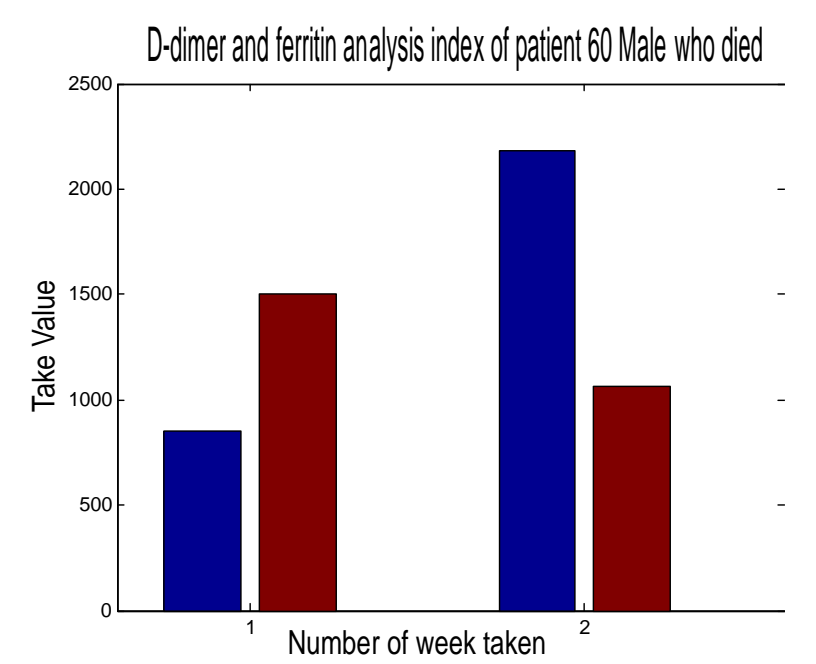

Graph 8 Dimero D and Ferritin analysis in patient 56 Source: Own [Matlab]

An important note in the statistical part of Dimero D and Ferritin is that in Dimero D the normal values must be below $100 \mathrm{ng} / \mathrm{ml}$ to be established as normal, above $500 \mathrm{ng} / \mathrm{ml}$ will mark blood clotting. In the case of fibrinogen, normal values are between 200 and $400 \mathrm{mg} / \mathrm{dl}$.

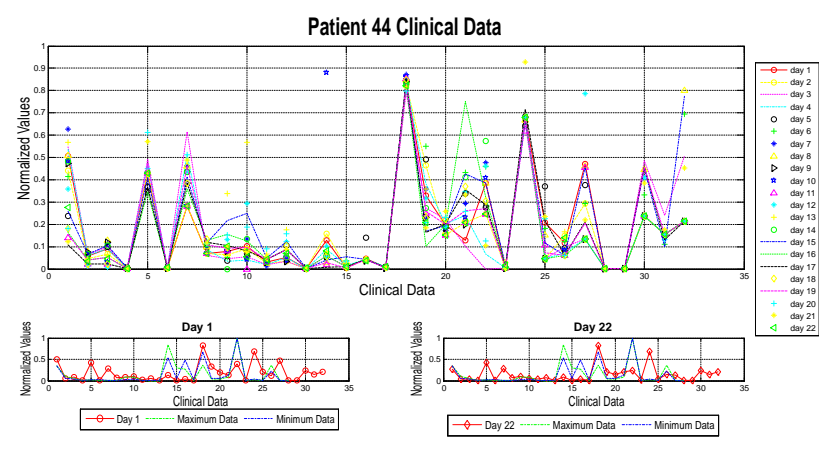

Graph 9 Patient behavior 44 Source: Own [Matlab]

It is important to mention that day-to-day charts were made of the clinical laboratories of the patients admitted to the CECCS to have a comparative study of their progress or setbacks in their stay or to know on which dates more changes were made in the patients, either for right or wrong. The graphs in Graph 9 show the laboratories obtained day by day during his stay, remembering that he died after 22 days, Figure describes 3 graphs, the first shows the day-today values of the laboratories, the second graph (lower part left) represents the laboratory values of the first day in the hospital, likewise the normal minimum and maximum values of each laboratory are added, the third graph (lower right) shows the laboratory values of the last day of hospital stay, the values are very different in both graphs to the average values of a normal patient.

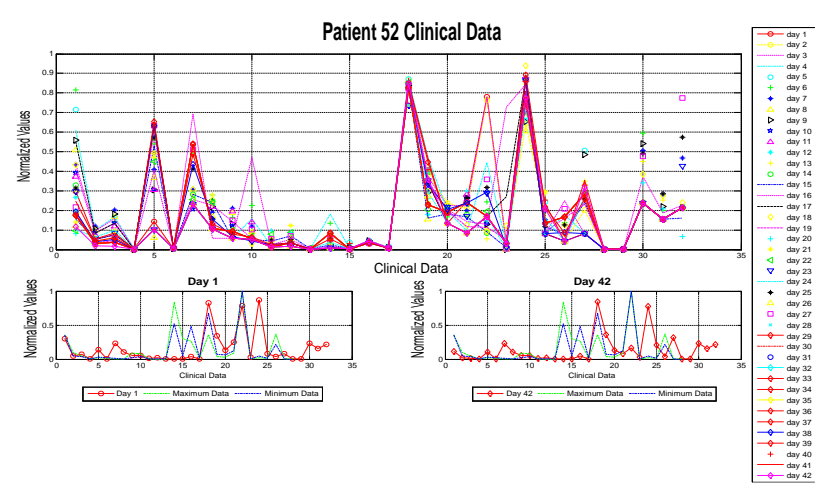

Graph 10 Behavior of the patient 52

Source: Own [Matlab]

The diagrams in Graph 10 show the laboratories obtained day by day during her stay, remembering that she was discharged after 42 days, Figure describes 3 graphs, the first shows the day-to-day values of the laboratories, the second graph (lower left) represents the laboratory values of the first day in the hospital, the third graph (lower right) shows the laboratory values of the last day of hospital stay, at some points the values are within the normal range.

YAÑEZ-VARGAS Israel, PRIETO-GARCÍA Daniela, DOÑATEÁLVAREZ Andrea and QUINTANILLA-DOMINGEZ Joel. Statistical evolution of clinical laboratories in patients admitted to the CECCS with SARS-COV-2. Journal of Quantitative and Statistical Analysis. 2021 


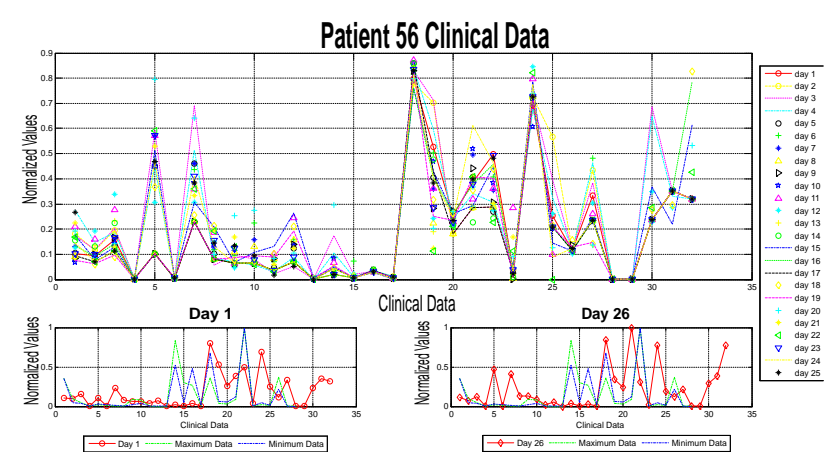

Graph 11 Patient behavior 56 Source: Own [Matlab]

The diagrams in Graph 11 show the laboratories obtained day by day during his stay, remembering that he was discharged after 26 days, Figure shows 3 graphs, in the first one you can see the day-to-day values of the laboratories, the second graph (lower left) represents the laboratory values of the first day in the hospital, the third graph (lower right) shows the laboratory values of the last day of hospital stay.

Based on the information described above, it was proposed to perform a data analysis with that collected from the first day of admission and the last day of hospitalization, the idea is to generate behavioral comparisons through the study of the relationship / correlation of the information.

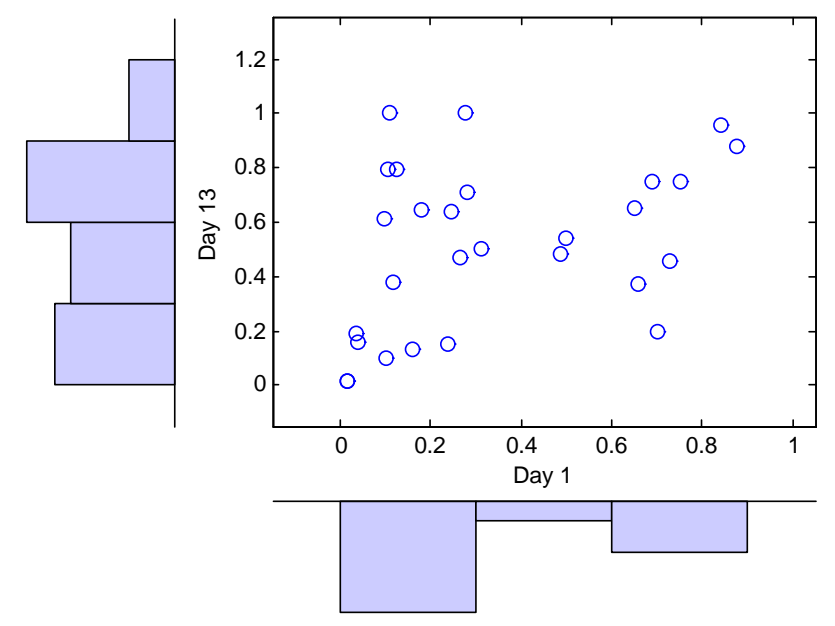

Graph 12 Laboratory relationship analysis of patient 17 Source: Own [Matlab]

Graph 12 shows the comparison of the two days, in which the normalized data are compared, in which the values obtained on that day are taken and its comparison, in which the patient, once he improves, should contain less dispersion of the information, so for patient number 17 (man) who unfortunately died, it is possible to observe the dispersion of the data.

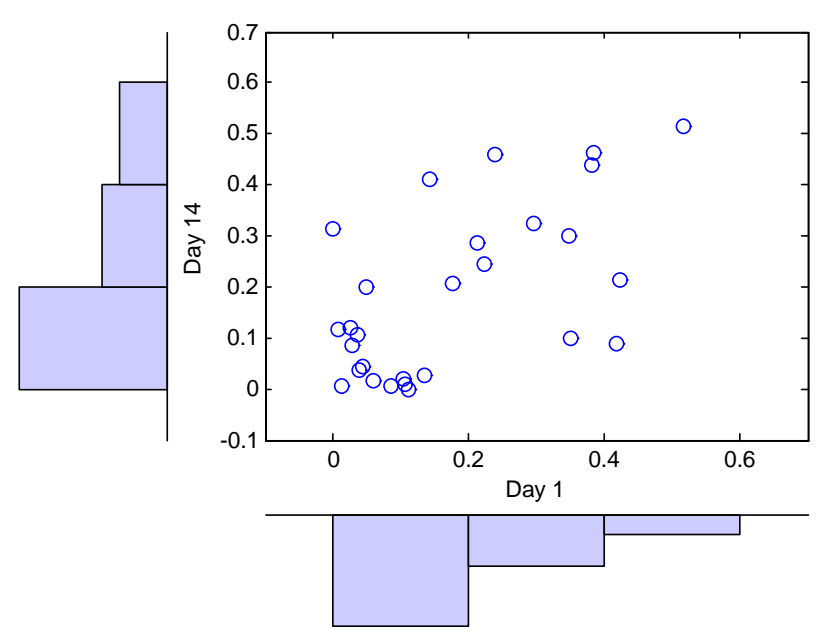

Graph 13 Laboratory relationship analysis of patient 16 Source: Own [Matlab]

In the case of Graph 13, we have the comparison described in the previous paragraph, for this case patient 16 (man) who was discharged, and the trend is to have a greater convergence / union of the data between the first and last stay day.

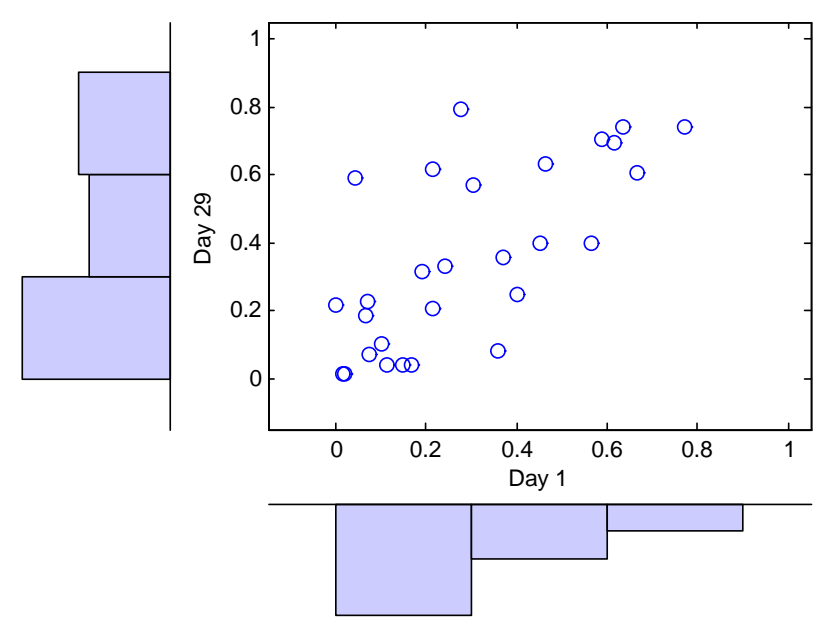

Graph 14 Laboratory relationship analysis of patient 2 Source: Own [Matlab]

Observing Graph 14 and as the study was described previously, there is the case of patient 2 (woman) who died, it can be noted that there is a slight relationship / correlation between the data. 


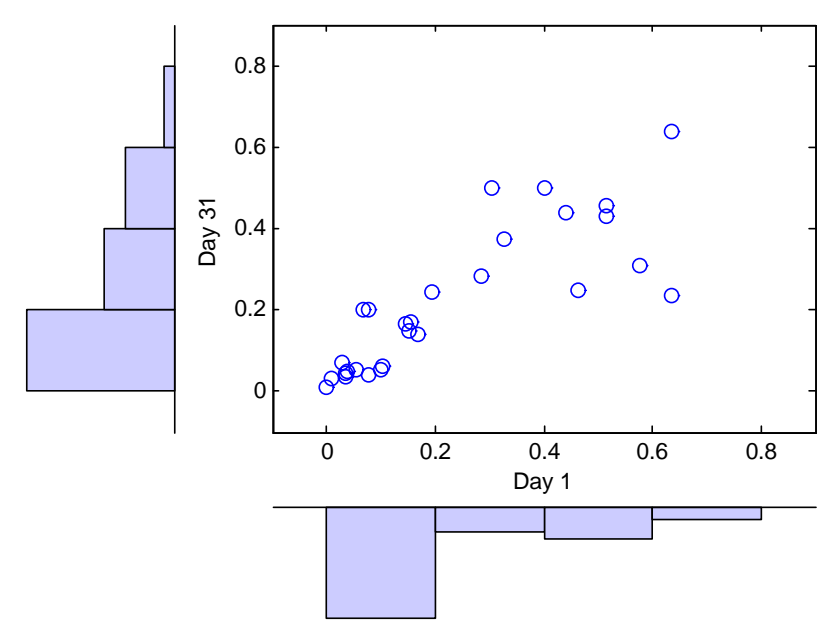

Graph 15 Behavior of patient 14 Source: Own [Matlab]

In the case of Graph 15 there is the comparison described in the previous paragraphs, for this case patient 14 (woman) was discharged, in her there is a greater relationship / correlation of the data, which has been a trend in the different tests that have been carried out.

It is possible to observe how there are more data that converge to similar results from both the first day and the last day, probably establishing that the patient has not worsened throughout his stay in the CECCS or even had improvements, that is why they begin to overlap multiple values generating a higher correlation between the data.

\section{Acknowledgments}

The authors would like to thank the State Center for Critical Care of Salamanca (CECCS), the doctor Dr. Cesar Centeno Fosado and the head of nurses Liliana Yañez Vargas for their support for the preparation of the article and for providing the database, as well as the Polytechnic University of Juventino Rosas.

\section{Conclusions}

This article performs an analysis of the clinical laboratories of the patients admitted to the CECCS, with the idea of locating important points that can help to know more about the disease, in addition to looking for a correlation between the new laboratory updates and the statistics, which was confirmed by finding that Dimero D and Ferritin are highly relevant in the disease through the use of variance as a statistical study.
The multiple graphs shown describe the behavior of the disease and that of the patients who died becomes relevant, denoting the laboratories that have the greatest changes and that will benefit in the future when carrying out the statistical study prior to intubation and the supply of some medications, as that it is tried to find if there is a benefit or not of them.

The final approach of the relationship from the first day of stay to the last day shows profound changes in patients and laboratories that do not remain normal, with the above it will be possible to know where a greater emphasis should be placed for possible stronger studies.

\section{References}

Coronavirus disease (COVID-19). (2020, 14 diciembre). Coronavirus disease (COVID-19) pandemic.

https://www.who.int/emergencies/diseases/nove 1-coronavirus-2019

Coronavirus - gob.mx. (2020, 14 diciembre). https://coronavirus.gob.mx/

Coronavirus Guanajuato. (2020, 10 abril). Recuperado 4 de mayo de 2021, de https://coronavirus.guanajuato.gob.mx/

Devore, J., 2012. Probability And Statistics For Engineering And The Sciences. 8th ed. Australia: Brooks/Cole, pp.28-38.

Gao, Y., Li, T., Han, M., Li, X., Wu, D., Xu, Y., Wang, L. (2020). Diagnostic utility of clinical laboratory data determinations for patients with the severe COVID-19. Journal of Medical Virology, 92(7), 791-796. https://doi.org/10.1002/jmv.25770

Gonzalez, R. C., \& Woods, R. E. (2008). Digital Image Processing ( $3^{\mathrm{a}}$ ed.). USA: Pearson/Prentice Hall.

Johnson, R. A., Miller, I., Freund, J. E., \& Olguín, V. C. (2012). Probabilidad y estadística para ingenieros. Pearson. 
Liu, Y., Yang, Y., Zhang, C., Huang, F., Wang, F., Yuan, J., Wang, Z., Li, J., Li, J., Feng, C., Zhang, Z., Wang, L., Peng, L., Chen, L., Qin, Y., Zhao, D., Tan, S., Yin, L., Xu, J., ... Liu, L. (2020). Clinical and biochemical indexes from 2019-nCoV infected patients linked to viral loads and lung injury. Science China Life Sciences, 63(3), 364-374.

https://doi.org/10.1007/s11427-020-1643-8

Pagana, K., \& Pagana, T. (2015). Laboratorio clínico: Indicaciones e interpretación de resultados (1.a ed.). Editorial El Manual Moderno

Rodriguez-Morales, A. J., Cardona-Ospina, J. A., Gutiérrez-Ocampo, E., Villamizar-Peña, R., Holguin-Rivera, Y., Escalera-Antezana, J. P., Sah, R. (2020). Clinical, laboratory and imaging features of COVID-19: A systematic review and meta-analysis. Travel Medicine and Infectious Disease,

34 ,

101623.

https://doi.org/10.1016/j.tmaid.2020.101623

YAÑEZ-VARGAS Israel, DOÑATEÁLVAREZ Andrea, QUINTANILLA DOMINGEZ Joel and AGUILERA GONZÁLEZ Gabriel. Laboratory data statistical analysis from CECCS' patients with or without SARS-CoV-2 (COVID-19). Journal of Quantitative and Statistical Analysis. 2020. 721: 9-17

Yun, H., Sun, Z., Wu, J., Tang, A., Hu, M., \& Xiang, Z. (2020). Laboratory data analysis of novel coronavirus (COVID-19) screening in 2510 patients. Clinica Chimica Acta, 507, 94-97. https://doi.org/10.1016/j.cca.2020.04.018 